\title{
2 The concept of impact assessment $^{1}$
}

\author{
Dariusz Kloza, ${ }^{*}$ Niels van DijK, ${ }^{* *}$ Simone Casiraghi, ${ }^{* * *}$ Sergi Vazquez MaY- \\ MIR $^{* * * *}$ and Alessia TANAS ${ }^{* * * *}$ \\ *Vrije Universiteit Brussel.E-mail: dariusz.kloza@vub.be. \\ ${ }^{* *}$ Vrije Universiteit Brussel, E-mail: niels.Van.Dijk@vub.be. \\ ${ }^{* * *}$ Vrije Universiteit Brussel.E-mail: simone.casiraghi@vub.be. \\ ****Vrije Universiteit Brussel, E-mail: sergi.Vazquez.Maymir@vub.be. \\ *****Vrije Universiteit Brussel, E-mail: Alessia.Tanas@vub.be.
}

\subsection{Introduction}

This Chapter introduces the concept of impact assessment, and thus lays down a foundation for the present textbook on integrated impact assessment for border control technologies. It intends to offer, in an accessible way, an overview of the said concept, eventually aiming to constitute a reference work for anybody interested in the topic. ${ }^{2}$

The Chapter is structured as follows: After the present introduction, it outlines the concept of impact assessment, namely its definition, terminology, and historical development, as well as its merits and drawbacks, ultimately exploring the possibility of integrating multiple evaluation techniques (Section 2.2). In Section 2.3, it offers 16 principles and conditions that apply to both the theory and practice of impact assessment (namely, the framework) and, in Section 2.4, it defines and describes, in a general manner, the consecutive or iterative steps to be undertaken in order to carry out an assessment process of any type and in any area of practice (namely, the method). This Chapter is to be read in conjunction with Chapter 8 and Annex 1, offering a tailored method and template, respectively, for a report arising from the process of integrated impact assessment for border control technologies.

This Chapter builds on the work of Vrije Universiteit Brussel's (VUB's) Brussels Laboratory for Data Protection \& Privacy Impact Assessments (d.pia.lab) ${ }^{3}$ and, wherever necessary, revises and updates it. However, nothing in this Chapter is to be considered 'final', as the concept of impact assessment is a 'living instrument', constantly necessitating a reflection on the most recent stage(s) of its development. 


\subsection{Impact assessment}

\subsubsection{Overview}

Generally speaking, impact assessment is an evaluation technique used to analyse the possible consequences of an initiative for a relevant societal concern or concerns (that is, a matter, or matters, of interest or importance), to determine whether this initiative could present danger to these societal concerns, with a view to supporting an informed decision on whether to deploy the initiative and under what conditions, and constitutes - in the first place - a means by which to protect those societal concerns. ${ }^{4}$

Analogous to the structure of risk management, ${ }^{5}$ the architecture of impact assessment typically consists of three main elements: framework, method and template. A framework constitutes an 'essential supporting structure'6 or organisational arrangement for something, which, in this context, defines and describes the conditions and principles of impact assessment. A method is a 'particular procedure for accomplishing or approaching something.7 It organises the practice of impact assessment and defines the consecutive or iterative steps to be undertaken in order to carry out the assessment process. A method corresponds to a framework and can be seen as a practical reflection of it. Finally, a template is a practical aid for the assessor. It takes the form of a schema to be completed following the given method. It structures the assessment process, guides the assessor through the process and, upon completion, serves as a final report from the process. It documents all the activities undertaken within a given assessment process, clarifies the extent of compliance with the law, and provides evidence as to the quality of the assessment process. ${ }^{8}$

This architecture is often supplemented by aids such as guidelines (handbooks, manuals), knowledge bases (for example, inventories of possible risks and corresponding countermeasures), and software to aid assessors in the assessment process by automating parts thereof; ${ }^{9}$ all such aids vary significantly in their quality and applicability.

The assessor is the actor who performs an assessment process, be it in-house (internal) or outsourced (external). The assessment process frequently necessitates expertise from more than a single domain, and hence is to be considered a collaborative activity. The team of assessors remains professionally independent from the leadership of a sponsoring organisation throughout the assessment process.

Finally, a benchmark is a societal concern or concerns that is/are in a need of governance and management, including protection and promotion, for example privacy and personal data protection. 


\subsubsection{History}

While some rudimentary anticipation of consequences has perhaps always been present in any form of decision-making, impact assessment and similar evaluation techniques formalised such anticipation of consequences as they grew out of the emergence of new and - at the time - poorly understood dangers to individual and collective societal concerns. These dangers were typically framed as uncertainty and risk, ${ }^{10}$ and it was understood to be in the interest of society to reduce them. For example, technology assessment (TA) emerged in 1960s in the United States, initially as a tool used by scientific committees to respond - largely, by advising policy makers on policy alternatives - to increasing public concerns relating to the negative social consequences of discoveries and inventions. TA was subsequently institutionalised as a means to ensure product safety, and gradually came to encompass a broader spectrum of issues relating to society and technology. ${ }^{11}$ In parallel, environmental impact assessment (EIA) surfaced as a response to the gradual degradation of the natural environment. ${ }^{12}$ These developments have aided the spread of evaluation techniques as a practice worldwide, and have resulted in the proliferation, and sometimes institutionalisation, of impact assessment in areas of practice ranging from healthcare, ${ }^{13}$ regulation (governance), ${ }^{14}$ ethics ${ }^{15}$ and surveillance practices ${ }^{16}$ to privacy ${ }^{17}$ and personal data protection. New types and areas of practice of impact assessment may well also emerge in the future.

Nevertheless, some 50 years after the emergence of the first types of impact assessment, this evaluation technique still failed to stand out as a clear-cut practice. Only in certain areas had it taken hold, such as TA, EIA or regulatory impact assessment (RIA), while in other areas it remains under development, for example in the areas of 'social' impact assessment ${ }^{18}$ or human rights impact assessment. ${ }^{19}$

The emergence and proliferation of privacy impact assessment (PIA) and - subsequently - data protection impact assessment (DPIA) is frequently attributed to four main factors, namely: (1) the development of science and technology, and their growing intrusiveness into individual lives and social fabric, ${ }^{20}(2)$ the increasing importance of the processing of personal data for contemporary economies, national security, scientific research, technological development and inter-personal relationships, among others, ${ }^{21}$ (3) the process of globalisation and (4) the negative experiences stemming from the use and misuse of personal data in the past, in both public and private sectors, and the growing awareness of all of these. ${ }^{22}$

Based on the experience of evaluation techniques in other areas of practice, it was expected that PIA and DPIA would become powerful vehicles for compliance with, and enforcement of, privacy and personal data protection law. ${ }^{23}$ PIA - and later DPIA - emerged in the 1990s and became institutionalised in different forms and at various levels of compulsion, first in common law jurisdictions, such as New Zealand, Australia, Canada and the United States. In Europe, the earliest policy for PIA was developed in the United Kingdom in 2007. ${ }^{24}$ 
The European Union (EU) has thus far put in place two sector-specific voluntary PIA policies: the first for radio-frequency identification (RFID) applications (2009), ${ }^{25}$ and the second for intelligent energy networks ('smart grids'; 2012-14). ${ }^{26}$ In a parallel development, the most recent 'better regulation' package (2017) advances privacy and personal data protection as just two of the many societal concerns under assessment in the processes of EU law- and policy-making; the other being (all other) fundamental rights, environmental and economic concerns. ${ }^{27}$

After the entry into force of the GDPR (2016), ${ }^{28}$ the Police and Criminal Justice Data Protection Directive (2016), ${ }^{29}$ and Regulation 2018/1725 on the protection of personal data processed by EU institutions, bodies, offices and agencies (2018), ${ }^{30}$ a mandatory policy for impact assessment was progressively introduced across the EU in the area of personal data protection. (By virtue of the European Economic Area (EEA) Agreement, the GDPR is likewise applicable in Norway, Iceland and Liechtenstein. $)^{31}$ In addition, the ePrivacy Regulation, proposed in 2017 and expected to be passed into law in 2021, if adopted in its current wording, would also require a process of DPIA to be conducted in specific situations. ${ }^{32}$

This proliferation of mandatory policies for impact assessment in the areas of privacy and personal data protection is also observed beyond the EU. The Council of Europe's recently finalised modernisation of 'Convention 108' (2018) ${ }^{33}$ introduced a similar requirement; the importance of the said Convention lies in the fact that it is open for signature also by non-Member States of the Council of Europe, hence influencing global standard setting. ${ }^{34}$ At the same time, various policies for PIA and DPIA, or - simply - for risk appraisal in the areas of privacy and personal data protection, have been introduced recently in Serbia (2018) ${ }^{35}$ and Switzerland (2020), ${ }^{36}$ and - beyond Europe - in Israel, Japan, South Africa and South Korea, among other states. In addition, a number of international organisations, such as the International Committee of the Red Cross, ${ }^{37}$ have introduced a requirement for such an assessment process into their by-laws.

\subsubsection{The benefits of impact assessment}

The benefit of impact assessment lies predominantly in its parallel contribution to informed decision-making and to the protection and promotion of societal concerns.

The former category, namely informed decision-making, usually attracts sponsoring organisations, as it brings with it benefits associated with a switch to anticipatory thinking. This permits those organisations to reflect on the consequences of their envisaged initiatives as well as on the means to - at least - minimise, or sometimes even avoid, negative and unintended consequences before they occur ('early warning'), leading to gains both in terms of resources and public trust.

Impact assessment can also ease compliance with legal and otherwise regulatory requirements (such as technical standards); for example, PIA 'can be an excellent entry point for applying the principles of Privacy by Design'. ${ }^{38}$ Being a 'best-efforts obligation', impact 
assessment constitutes evidence of due diligence, which can potentially limit or even exclude legal liability. ${ }^{39}$ In parallel, impact assessment allows sponsoring organisations to explain themselves to regulatory authorities (that is, to give account of) as to how they have acquitted themselves of certain responsibilities (that is, accountability) often facilitating part(s) of the work of such authorities. Eventually, impact assessment, if conducted in a transparent manner, may increase public confidence by showing that a sponsoring organisation takes societal concerns seriously. In addition, the private sector might be particularly interested in using impact assessment to demonstrate corporate social responsibility.

The latter category, namely protection and promotion of societal concerns, is usually attractive for public authorities because a requirement to conduct the assessment process helps them in fulfilling their mission to offer practical and efficient protection of relevant societal concerns (for example, certain human rights, such as privacy or personal data protection) for the benefit of the individual and society at large. For individuals and social groups, impact assessment is a means to voice their concerns (primarily through stakeholder involvement), which contributes to procedural justice. ${ }^{40}$ Impact assessment seeks to accommodate diverse interests and consequently contributes to the drawing of a 'thin red line' between legitimate yet seemingly competing interests, for example national security and the protection of personal data (for instance, in DPIA), or the competitiveness of national economy and environmental protection (for instance, in EIA). In comparison with other protection tools, impact assessment may provide a wider scope in this regard than, for example, compliance checks, which can often be reduced to mere 'tick-box' exercises.

\subsubsection{The drawbacks of impact assessment}

Critics of impact assessment have argued that it unnecessarily burdens sponsoring organisations, adding to an already-overgrown bureaucracy, causing unnecessary expenditure and delays in decision-making, or even slowing the deployment of an initiative in question. It is thus no surprise that there is a recurrent wish for the process of impact assessment to be quick, simple and cheap. ${ }^{41}$ Opponents underline the complexity of the assessment process in practice, the difficulties it brings, the lack of practical experience, and minimal or non-existent guidance and oversight. They further question its added value over other evaluation techniques, for example, compliance checks, as well as its efficacy, pointing out the broad discretion often afforded as to whether and how an assessment process should be conducted.

Impact assessment is often criticised for contributing to achieving only the minimum necessary compliance with regulatory requirements, with the least amount of effort, or instrumentally, in order to legitimise intrusive initiatives. Some sponsoring organisations are criticised for focusing on assessment processes in an abstract fashion, instead of using them as a means to address the consequences of a given envisaged initiative. Such organisations often confuse impact assessment with auditing. They incorrectly consider the consequences as being applicable only to themselves (for example, reputational or 
financial risks), rather than assessing the consequences for individuals and the public at large. Ultimately, impact assessment is often performed too late, that is, when the design of an initiative can no longer be meaningfully influenced. Critics further suggest that when impact assessment is compulsory, it represents a regulatory requirement too narrow in scope, allowing significantly dangerous initiatives to escape scrutiny. When an assessment process has been performed, it usually lacks transparency, that is, the process as a whole is opaque, hard for the layperson to understand (for example, due to a high level of technical complexity) and final results (in particular, the report including recommendations) are difficult, if not impossible, to find. It is often also criticised for failing to involve stakeholders, or giving them limited scope, therefore making their participation meaningless.

All in all, impact assessment is first and foremost an aid for decision-making. It is no 'silver bullet' solution: the quality of advice, and hence protection and promotion it can offer, depends on the way it is used, on the support it receives from public authorities, and, in the long run, on the oversight exercised by regulatory authorities and courts of law alike. Impact assessment does not come without difficulties, yet with straightforward application and clear methods, supported by guidance, advice and oversight, impact assessment can ultimately contribute to a more robust protection and promotion of societal concerns. ${ }^{42}$

\subsubsection{Integration of evaluation techniques}

Following the principles of the relevance of the benchmark and its adaptiveness (cf. infra), each assessment process is tailored (adapted) to the needs and reality of the initiative under assessment. In this regard, experience has shown that multiple types and areas of impact assessment - and, more broadly, evaluation techniques - can be integrated within a single assessment process. For example, the processes of PIA and DPIA might be combined if an envisaged initiative touches upon both societal concerns of privacy and personal data.

Such integration of evaluation techniques can be beneficial for at least three reasons: (1) since 'everything is inherently interconnected', ${ }^{43}$ integration might render a more complete picture for decision-makers, (2) it leads to greater efficiency, i.e. a maximisation of productivity with minimum wasted effort or expense, and (3) it allows for inclusion of aspects not required in legally mandated evaluation techniques. ${ }^{44}$ Such integration bears fruit on the condition that the integrated method, and in particular its benchmark, is internally coherent and not contradictory. In other words, integration of diverse types and areas of practice of impact assessment leads to an outcome that is greater than the sum of its parts.

However, while integration may contribute to efficiency, it could also lead to the subordination of certain elements of the benchmark, particularly 'those that are supposed to have their status raised in decision making through specific assessment instruments, ${ }^{35}$ an outcome that is not desired. For example, the process of human rights impact assessment is intended to deal with the entirety of human rights, yet largely at the expense of the attention normally given to each human right were they to be assessed individually. 


\subsection{The framework for impact assessment}

The framework for impact assessment sets foundations for both the theory and practice of impact assessment. It consists of 16 conditions and principles applicable to any type or area of practice of impact assessment.

Building on a comparative analysis and critical appraisal of multiple frameworks for impact assessment, these conditions and principles are: ${ }^{46}$

1. Systematic process. Impact assessment is a systematic process undertaken in accordance with an appropriate method and conducted in a timely manner. It starts early in the lifecycle of a single initiative, or a limited number of similar initiatives (for example, a proposed technology or a piece of legislation), prior to deployment. It continues throughout the development life-cycle and beyond as the society changes, dangers evolve and knowledge grows. It is revisited when needed, thus continuously influencing the design of the initiative under assessment.

2. Relevant benchmark. The assessment process analyses the possible future consequences of deploying a given initiative, or a set of similar initiatives, against the relevant societal concerns, both individual and collective, commensurate with its type (for example, DPIA pertains to the protection of individuals whenever their personal data are being processed and EIA pertains to the natural and human environment). Threshold analysis (scoping, context establishment, etc.) and stakeholder involvement help in determining and maintaining a list of such concerns. Whenever necessary, multiple types of impact assessment are performed for a given initiative, possibly in an integrated manner.

3. Rational requirement. Not all initiatives require an assessment process. Such a need is therefore determined by factors such as the nature, scope, context and purpose of the initiative under assessment, the number and types of individuals affected, etc. Impact assessment is, however, to be considered compulsory at least for initiatives capable of causing severe negative consequences to relevant societal concerns.

4. Appropriate method. There is no 'silver bullet' method for performing the assessment process. What matters is the choice of an appropriate assessment method allowing for the most comprehensive understanding of possible future consequences of the envisaged initiative.

5. Recommendations. The assessment process not only identifies, describes and analyses possible future consequences - positive or negative, intended or unintended - of an initiative under assessment, but also identifies, describes, analyses and prioritises possible solutions (recommendations) to address these consequences.

6. Best efforts endeavour. Impact assessment constitutes a 'best efforts obligation'. Since it is impossible to reduce negative consequences in absolute terms (as it is to maximise positive ones), sponsoring organisations react to them to the best of their abilities, depending upon the state-of-the-art and, to a reasonable extent, available resources. 
7. Assessor's competence. The assessment process requires the assessor, or team of assessors, to have sufficient knowledge and know-how, corresponding to the type and area of practice of impact assessment at stake, for successful completion of the process.

8. Assessor's professional independence. The independence of the assessor - be they external or in-house - is ensured: they do not seek nor accept any instruction, avoid any conflict of interest, avoid any (personal) bias, and have sufficient resources (namely: time, money, workforce, knowledge and know-how, premises, and infrastructure) at their disposal.

9. Documentation and transparency. The assessment process is documented in writing or other permanent form, and is made available for unrestricted public access. The public at large is informed about the assessment process, its terms of reference, in particular the method, and its progress. Both draft and final assessment reports are easily accessible. Such access is granted without prejudice to state secrets, trade secrets, personal data or otherwise privileged information.

10. Deliberativeness. The assessment process is deliberative in the sense that it involves the participation of stakeholders. External stakeholders, be they individuals or civil society organisations affecting, affected, concerned by or merely interested in the initiative under assessment, or the public at large, are identified and meaningfully informed about it, their voices are actively sought and duly taken into consideration (namely through a process of consultation and - possibly - co-decision). Information given and sought is robust, accurate and inclusive. Individuals and/or their representatives have effective means of challenge, for example, in a court of law or similar tribunal, should they be denied involvement or should their views be ignored. In parallel, anyone within the sponsoring organisation (that is, internal stakeholders) is to participate in the assessment process under the same conditions. Exceptions to stakeholder involvement, if justified, are interpreted narrowly.

11. Accountability. The sponsoring organisation is accountable for the assessment process. Decision-makers within such an organisation choose, among other things, the method of assessment and assessors that will conduct it. They eventually approve the final assessment report and, in a subsequent process, may monitor the implementation of proposed solutions (recommendations). An external entity (for example, a regulatory authority or an auditing body) scrutinises the quality of the assessment process; the selection criteria are transparent. Therefore, a sponsoring organisation is able to demonstrate the satisfactoriness of the undertaken assessment process. However, in situations where an assessment process is made compulsory by law (for example, in DPIA in the EU, when there is a likelihood of a high risk to the rights and freedoms of data subjects), non-compliance and malpractice are proportionately sanctioned.

12. Simplicity. The assessment process is simple, that is, not unduly burdensome. The method serves those who use it, and is therefore structured, coherent, easily understan- 
dable, and avoids prescriptiveness, over-complication and abuse of resources. There is however an inherent trade-off between the simplicity of use and the technical sophistication and accuracy of the assessment.

13. Adaptiveness. Impact assessment is adaptive to the characteristics of an initiative under assessment and its sponsoring organisation ('one size does not fit all') in terms of, for example, type and complexity thereof (e.g. technology development, scientific research or legislative proposals) or the type and number of individuals concerned (affected) (e.g. nuclear safety is not to be considered in the same manner as personal data protection). The method and the template for impact assessment might be modular, or 'consisting of separate parts that, when combined, form a complete whole, ${ }^{47}$ allowing the addition and/or swapping of one module for another, as impact assessment is responsive to geographical and cultural differences, as well as to variations between legal systems (jurisdictional differences). In addition, as impacts can be appraised in many ways, assessors might resort to other evaluation techniques deemed more appropriate, entirely or in part, possibly in an integrated manner.

14. Inclusiveness. Impact assessment is inclusive. This ensures as many stakeholders (including experts and laypersons), relevant societal concerns and relevant development phases as possible, commensurate with the societal concerns at stake, and the type and area of practice of impact assessment, are included in the assessment process.

15. Receptiveness. Impact assessment is receptive. The framework, method, template and process evolve as a result of learning from previous experience in parallel evaluation techniques (for example, TA, EIA, risk management, etc.), knowledge from related disciplines (for example, law), and changes within society.

16. Supportive environment. Impact assessment requires a supportive environment in order to bear fruit. It needs, inter alia, continuous high-level support from policy-makers, and a spirit of cooperation among external and internal stakeholders. Regulators offer guidance and practical assistance in the assessment process, in the form of adequate training, guidelines, explanations and advice, among other things.

\subsection{A generic method for impact assessment}

The generic method lays the foundations for specific methods for impact assessment of multiple types and in multiple areas of practice. The generic method consists of ten steps (six consecutive steps, three steps executed throughout the entire process, and one step conducted afterwards), grouped into four phases. Some of these steps follow a logical sequence, namely the outcome of one step informs a subsequent one, while others are a function of the principles and conditions embodied in the framework. 
These steps, building on a comparative analysis and critical appraisal of multiple methods for conducting the assessment process, are as follows: ${ }^{48}$

Phase I: Preparation of the assessment process

1) Screening (threshold analysis). This step determines whether the process of impact assessment is warranted or necessary for a planned initiative or a set of similar initiatives in a given context. The screening is based on an initial yet sufficiently detailed description of the said initiative, both contextual and technical. The determination is made in accordance with threshold criteria, both internal (i.e. the organisation's own policies) and external (i.e. those set out in legal or other regulatory requirements), or ad hoc criteria, such as public pressure. If an assessment process is neither warranted nor necessary, the entire process is then concluded with a reasoned statement of no significant impact.

2) Scoping. This step, on the basis of the initial description, is taken to determine the extent of the assessment process and hence identifies:

a) societal concerns, and their scope, that may be touched on by a planned initiative, such as privacy, personal data protection, (applied) ethics, or the natural and human (biophysical) environment, and the corresponding legal or other regulatory requirements; these concerns will constitute a benchmark of a given assessment process;

b) categories of stakeholders who might affect, be affected by, be concerned with or be interested in the envisaged initiative(s), or who possess knowledge thereof (experts), as well as the level of their involvement; stakeholders might suggest further stakeholders to be included;

c) techniques and methods for the appraisal of impacts and for stakeholder involvement, including public participation in decision-making, which will be used throughout a given assessment process;

d) other evaluation techniques beyond the process of impact assessment that might be necessary or warranted in order to ensure the completeness of the information used in the decision-making process (for example, TA or EIA); and

e) anything else, as practicable.

It may be the case that not all of these elements and people are identifiable at the beginning of the assessment process, and hence their identification might need to be revised periodically.

3) Planning and preparation. This step defines the terms of reference for the execution of the assessment process. Not all of its elements, however, are of equal importance and applicability. These terms include, among others:

a) the objectives;

b) the criteria for the acceptability of negative impacts;

c) the necessary resources (namely: time, money, workforce, knowledge, know-how, premises and infrastructure);

d) the procedures and time-frames for the assessment process;

e) the team of assessors (in-house or outsourced), their roles and responsibilities, and assurance of their professional independence; 
f) a detailed list of the stakeholders to be involved (including, for example, their contact details) and a consultation plan, if necessary;

g) the criteria triggering a revision of the assessment process; and

h) the continuity of the assessment process in the event of, for example, changes in the actors involved in the assessment process, disruption, natural disasters or utility failures.

\section{Phase II: Assessment}

4) Systematic description. This step, on the basis of the initial description (see Step 1), provides a sufficiently detailed, two-part account of the planned initiative. First, there is a contextual description, which typically consists of, but is not limited to, a description of:

a) the planned initiative(s) and of the sponsoring organisation;

b) the context of deployment of the initiative;

c) the need for the initiative;

d) possible interference(s) with societal concern(s); and

e) the expected benefits and drawbacks.

Second, a technical description. In the case of EIA, this gives an account of, for example, the affected components of the biophysical environment, and, in the case of DPIA, it describes, for example, the categories of personal data and their flows within a processing operation. This description may be subjected to alterations and amendments as the assessment process progresses.

5) Appraisal of impacts. In this step, the impacts of the envisaged initiative are evaluated in accordance with the pre-selected techniques (cf. Step 2). These impacts pertain to the societal concern(s) that might be touched upon by the planned initiative, and to the stakeholders who are largely external to the sponsoring organisation. Typically, this appraisal consists of - at least - a detailed identification, analysis and evaluation of the impacts.

The appraisal techniques range from risk analysis (qualitative or quantitative risk management, or a combination of the two), scenario analysis (planning) and technology foresight, through a legal and regulatory compliance check, legal interpretation techniques, and a proportionality and necessity assessment, to a cost-benefit analysis (CBA) and a strengths, weaknesses, opportunities and threats (SWOT) analysis.

6) Recommendations. In this step, concrete, detailed measures (controls, safeguards, solutions, etc.), their addressees, their priorities and the time-frames for addressing them are proposed to minimise the negative impacts of the planned initiative and, if possible, to maximise the positive ones. The assessors justify the distinction made between 'negative' and 'positive' impacts, since this distinction is contextual and subjective. The assessors may take stock of the measures already implemented. On this basis, after the conclusion of the assessment process, the leadership of the sponsoring organisation takes a decision on whether or not to deploy the initiative. An initiative is normally cancelled altogether if the negative impacts are unacceptable (see Step 3b); to carry out such an initiative would be exceptional and would require sufficient justification. 


\section{Phase III: Revisiting}

7) Revisiting. In this step, a decision is made on whether or not to carry out the process again, entirely or in part. This step may occur every time the envisaged initiative is modified (before or after its deployment) or every time the context in which it is going to be deployed, or has already been deployed, changes. This step also ensures the continuity of the assessment process, such as in the case of a transfer of the initiative to another sponsoring organisation.

\section{Ongoing phase}

8) Stakeholder involvement, including public participation, in decision-making. This is an ongoing, cross-cutting step that runs throughout the entire assessment process, in which stakeholders, including the public and/or their representatives, take part in the assessment process.

Understood broadly, a stakeholder is someone who holds an interest in something, regardless of whether or not they are aware of this and of whether the interest is articulated directly or not. In the context of impact assessment, a stakeholder is an actor that is or might be affecting, affected, concerned by or be interested in the outcome of a planned initiative. A stakeholder may also be an expert who possesses specific knowledge and know-how about the initiative. The concept of stakeholder is therefore open-ended and can include the public (laypeople, etc.), decision-makers, experts, and more. Stakeholders can be individuals or collective entities, regardless of whether they are formally (legally) recognised or not. They may be societal groups, communities, nations, the public at large, civil society organisations, etc. There are multiple (groups of) stakeholders, and hence they can be grouped into internal (e.g. employees or work committees) and external (e.g. customers or non-governmental organisations) ones, and primary (i.e. those with a direct stake in the initiative, for example, investors) and secondary (i.e. those with an indirect interest yet influential, for example, the state) ones, or they can be classified by their attributes, including, but not limited to, power, legitimacy and urgency.

Stakeholder involvement constitutes an integral component of the assessment process, and is normally omitted only in exceptional situations. For example, stakeholder involvement may be judged unnecessary because of similarities with an earlier, similar initiative, because no promising new insights or thoughts are to be gained, or because it would require an effort that would be disproportionate to the results. A decision not to involve stakeholders, or to deviate from the results of such an involvement, must be reasoned and documented. Whenever stakeholder involvement is mandatory, legal remedies are available for the entitled stakeholders, provided that their involvement is absent or insufficient, commensurate with the level of involvement pursued in a given assessment process. In any case, stakeholder involvement does not give rise to any negative consequences for its participants (for example, exploitation). Personal data of identified stakeholders are appropriately protected. 
The level of stakeholder involvement can range from: (a) merely being informed or taught about a planned initiative (low level); to (b) dialogue and consultation, in which the stakeholders' views are sought and taken into consideration (middle level); or even to (c) co-decision by the stakeholders and a sponsoring organisation about the deployment of the initiative in question and, subsequently, partnership with the stakeholders in its implementation (high level). ${ }^{49}$

From a practical viewpoint, typically stakeholders are first identified, then informed and consulted and, eventually, their views are considered (in case of consultation) or they are asked for an agreement (in case of co-decision). Information given and sought is robust, accurate, inclusive and meaningful. Information is given to stakeholders in plain language, and hence may require the preparation of specific documentation, for example technical briefings and/or translations. Stakeholders are involved with due respect for confidentiality, including state secrets, trade secrets, personal data or otherwise privileged information. Having gathered the viewpoints of the stakeholders, the assessor considers and takes a position on their views, i.e. on whether they accept them or not; especially in the case of the latter, the assessors are to provide exhaustive justification. (Stakeholders are not assessors; the former provide input, which the latter subsequently take into account or reject.)

There are a plethora of techniques for engaging stakeholder involvement, ranging from information notices to interviews, questionnaires and surveys, to focus groups, roundtables, workshops and citizens' panels, and including structured techniques, such as a 'world café" or use of the 'Delphi method..$^{50}$ An appropriate technique, or a combination of techniques, is selected depending on the level of stakeholder involvement desired, the planned initiative, the context of the deployment of the initiative, and the resources at the disposal of the sponsoring organisation.

Stakeholder involvement can bring several benefits to the assessment process (for example, enhancement of its quality, credibility and legitimacy) and to the outcome (for example, the decision-making process being better-informed), to be contrasted with its drawbacks, which include, inter alia, the question of representativeness (overor under-representation), fairness (for example, manipulation, 'astroturfing'), ${ }^{51}$ reluctance, communication barriers, conflict between public and private interests, and the resource-intensive nature of the entire stakeholder involvement process.

9) Documentation. This is an ongoing, cross-cutting step, and runs throughout the entire process. Records are kept, in writing or in another permanent form, of all activities undertaken during the assessment process. This step includes the preparation of a final report stemming from the assessment process (or a statement of no significant impact, where applicable). The full spectrum of documentation from a given assessment process, preferably in an electronic format, may be made publicly available, centrally registered, and/or presented for inspection upon request (with due respect for legitimate confidentiality concerns). 
10) Quality control. In this ongoing, cross-cutting step that runs throughout the entire assessment process, the adherence to a standard of performance is checked (procedural, substantive, or both), either internally (for example, through progress monitoring or a review by the sponsoring organisation) or externally (for example, by an independent regulatory authority through an audit, or by a court of law), or both. The quality control, regardless whether structured or ad hoc, can equally well occur during or after the assessment process, or both.

The above-mentioned method for assessing the impacts of an initiative on a societal concern, or concerns, is of a generic nature and needs to be tailored to the specificities and needs of a given area of practice, of the stakeholders (including the public) involved, and of the context of use. Consistent with its purpose, the present textbook offers, in Chapter 8 and Annex 1, a tailor-made method and template, respectively, for integrated impact assessment of border control technologies.

\section{Endnotes}

1. The research leading to this Chapter has received funding from the European Union under multiple programmes and schemes (European Commission Directorate-General for Justice and Consumers' action grants, the $7^{\text {th }}$ Framework Programme for Research and Technological Development (FP7), and the Horizon 2020 Framework Programme for Research and Innovation (H2020)), and from l'Institut d'Encouragement de la Recherche scientifique et de l'Innonvation de Bruxelles (Innoviris). The contents are the sole responsibility of the authors, and can in no way be taken to reflect the views of any of the funding agencies.

2. References to legal provisions without any further specification pertain to the General Data Protection Regulation (GDPR, Regulation (EU) 2016/679 of the European Parliament and of the Council of 27 April 2016 on the protection of natural persons with regard to the processing of personal data and on the free movement of such data, and repealing Directive 95/46/ EC [General Data Protection Regulation], OJ L 119, 4.5.2016, p. 1-88). The Chapter reflects the law and practice as they stood on 31 March 2021; all hyperlinks are valid as of that day.

3. This Chapter builds on, and sometimes incorporates, the updated and revised text of two earlier works we co-authored: Dariusz Kloza et al., "Data Protection Impact Assessments in the European Union: Complementing the New Legal Framework towards a More Robust Protection of Individuals", d.pia.lab Policy Brief (Brussels: VUB, 2017), 1-4, https:// doi.org/10.31228/osf.io/b68em; Kloza et al., "Towards a Method for Data Protection Impact Assessment: Making Sense of GDPR Requirements", 1-8. See also: Dariusz Kloza et al., "Data Protection Impact Assessment in the European Union: Developing a Template for a Report from the Assessment Process," d.pia.lab Policy Brief (Brussels: VUB, 2020), https://doi. org/10.31228/osf.io/7qrfp. We furthermore thank - in alphabetical order - István Böröcz, Alessandra Calvi, Raphaël Gellert, Nikolaos Ioannidis, Ioulia Konstantinou, Eugenio Mantovani, Paul Quinn and Sara Roda for their contributions to the development of the d.pia.lab's architecture of impact assessment.

4. Kloza et al., "Towards a Method for Data Protection Impact Assessment: Making Sense of GDPR Requirements." 
5. In its guidelines on risk management, the International Organization for Standardization (ISO) distinguishes between the principles, the framework and the process of risk management. See: ISO, Risk management - Guidelines, ISO 31000:2018, Geneva, https://www.iso. org/obp/ui\#\#iso:std:iso:31000:ed-2:v1:en.

6. Oxford Dictionary of English.

7. Oxford Dictionary of English.

8. Kloza et al., "Data Protection Impact Assessment in the European Union: Developing a Template for a Report from the Assessment Process."

9. See, for example, International Association of Privacy Professionals [IAPP] (2020) 2020 Privacy Tech Vendor Report, Portsmouth, NH, https://iapp.org/resources/article/privacy-tech-vendor-report.

10. See, for example, David Garland, “The Rise of Risk," in Risk and Morality, ed. Aaron Doyle and Diana Ericson (Toronto: University of Toronto Press, 2003), 48-83, https://doi. org/10.3138/9781442679382-005.

11. See, for example, Emilio Quincy Daddario, “Technology Assessment. Statement of Emilio Q. Daddario, Chairman, Subcommittee on Science, Research, and Development of the Committee on Science and Astronautics, U.S. House of Representatives" (Washington: United States Government Publishing Office, 1967); Joseph F. Coates, "Some Methods and Techniques for Comprehensive Impact Assessment," Technological Forecasting and Social Change 6 (1974): 341-57, https://doi.org/10.1016/0040-1625(74)90035-3; Rinie van Est and Frans W. A. Brom, “Technology Assessment, Analytic and Democratic Practice," Encyclopedia of Applied Ethics 4 (2012): 306-20, https://doi.org/10.1016/B978-0-12-373932-2.00010-7; Armin Grunwald, Technology Assessment in Practice and Theory (Abingdon: Routledge, 2018), https://doi.org/10.4324/9780429442643.

12. Bram F. Noble, Introduction to Environmental Impact Assessment. A Guide to Principles and Practice (Toronto: Oxford University Press, Canada, 2015).

13. See, for example, David Banta, Finn Børlum Kristensen, and Egon Jonsson, "A History of Health Technology Assessment at the European Level," International Journal of Technology Assessment in Health Care 25, no. 1 (2009): 68-73, https://doi.org/10.1017/S0266462309090448.

14. See, for example, Claire A. Dunlop and Claudio M. Radaelli, Handbook of Regulatory Impact Assessment (Cheltenham: Edward Elgar, 2016).

15. See, for example, Elin Palm and Sven Ove Hansson, "The Case for Ethical Technology Assessment (ETA)," Technological Forecasting and Social Change 73, no. 5 (2006): 543-58, https://doi.org/10.1016/j.techfore.2005.06.002.

16. See, for example, David Wright and Charles D. Raab, "Constructing a Surveillance Impact Assessment," Computer Law and Security Review 28, no. 6 (2012): 613-26, https://doi. org/10.1016/j.clsr.2012.09.003.

17. See, for example, David Wright and Paul De Hert, eds., Privacy Impact Assessment (Dordrecht: Springer, 2012), https://doi.org/10.1007/978-94-007-2543-0; Paul De Hert, Dariusz Kloza, and David Wright, "Recommendations for a Privacy Impact Assessment Framework for the European Union" (Brussels - London, 2012), https://researchportal.vub.be/ files/14231615/PIAF_D3_final.pdf. See also Roger Clarke's work on PIA, http://www.rogerclarke.com/DV/\#PIA.

18. See, for example, Henk Becker and Frank Vanclay, The International Handbook of Social Impact Assessment (Edward Elgar, 2003), https://doi.org/10.4337/9781843768616; Ana Maria Esteves, Daniel Franks, and Frank Vanclay, "Social Impact Assessment: The State of the Art," Impact Assessment and Project Appraisal 30, no. 1 (2012): 34-42, https://doi.org/10.1080/146 15517.2012.660356.

19. See, for example, Nora Götzmann, Handbook on Human Rights Impact Assessment (Edward Elgar, 2019), https://doi.org/10.4337/9781788970006. 
20. Roger Clarke, "Privacy Impact Assessment: Its Origins and Development," Computer Law \& Security Review 25, no. 2 (2009): 123-35, https://doi.org/10.1016/j.clsr.2009.02.002.

21. Rob Kitchin, The Data Revolution: Big Data, Open Data, Data Infrastructures and Their Consequences, 2014, https://doi.org/10.4135/9781473909472. See also M Castells, The Rise of the Network Society: The Information Age: Economy, Society, and Culture (Malden, MA: Wiley, 2010).

22. See, for example, David Lyon, Surveillance Studies: An Overview (Cambridge: Polity Press, 2007).

23. On the experience from carrying out PIA or DPIA processes, see, for example: Jennifer Stoddart, "Auditing Privacy Impact Assessments: The Canadian Experience," in Privacy Impact Assessment, ed. David Wright and Paul De Hert (Dordrecht: Springer, 2012), 419-36; Kush Wadhwa and Rowena Rodrigues, "Evaluating Privacy Impact Assessments," Innovation: The European Journal of Social Science Research 26, no. 1-2 (2013): 161-80, https://doi.org/1 0.1080/13511610.2013.761748; Jeroen Van Puijenbroek and Jaap Henk Hoepman, "Privacy Impact Assessment in Practice: The Results of a Descriptive Field Study in the Netherlands," in CEUR Workshop Proceedings 1873, 2017: 1-8; Laurens Sion et al., "DPMF: A Modeling Framework for Data Protection by Design," Enterprise Modelling and Information Systems Architectures (EMISAJ) 15, no. 10 (2020): 1-53, https://doi.org/10.18417/emisa.15.10.

24. Clarke, "Privacy Impact Assessment: Its Origins and Development."

25. European Commission, Recommendation on the implementation of privacy and data protection principles in applications supported by radio-frequency identification, Brussels, 12 May 2009, C(2009) 3200 final.

26. European Commission, Recommendation on the Data Protection Impact Assessment Template for Smart Grid and Smart Metering Systems, 2014/724/EU, OJ L 300, 18.10.2014, pp. 63-68.

27. European Commission, Better Regulation Guidelines, Brussels, 7 July 2017, SWD (2017) 350.

28. Regulation (EU) 2016/679 of the European Parliament and of the Council of 27 April 2016 on the protection of natural persons with regard to the processing of personal data and on the free movement of such data, and repealing Directive 95/46/EC (General Data Protection Regulation), OJ L 119, 4.5.2016, p. 1-88.

29. Directive (EU) 2016/680 of the European Parliament and of the Council of 27 April 2016 on the protection of natural persons with regard to the processing of personal data by competent authorities for the purposes of the prevention, investigation, detection or prosecution of criminal offences or the execution of criminal penalties, and on the free movement of such data, and repealing Council Framework Decision 2008/977/JHA, OJ L 119, 4.5.2016, p. 89-131.

30. Regulation (EU) 2018/1725 of the European Parliament and of the Council of 23 October 2018 on the protection of natural persons with regard to the processing of personal data by the Union institutions, bodies, offices and agencies and on the free movement of such data, and repealing Regulation (EC) No 45/2001 and Decision No 1247/2002/EC, OJ L 295 , 21.11.2018, p. 39-98.

31. Decision of the EEA Joint Committee No 154/2018 of 6 July 2018 amending Annex XI (Electronic communication, audiovisual services and information society) and Protocol 37 (containing the list provided for in Article 101) to the EEA Agreement [2018/1022], OJ L 183, 19.07.2018, pp. 23-26.

32. Proposal for a Regulation of the European Parliament and of the Council concerning the respect for private life and the protection of personal data in electronic communications and repealing Directive 2002/58/EC (Regulation on Privacy and Electronic Communications), 2017/0003(COD). See also https://oeil.secure.europarl.europa.eu/oeil/popups/ficheprocedure.do? reference $=2017 / 0003(\mathrm{COD}) \& \mathrm{l}=\mathrm{en}$.

33. Protocol amending the Convention for the Protection of Individuals with regard to Automatic Processing of Personal Data, Strasbourg, 10 October 2018, CETS No. 223. 
34. Graham Greenleaf, "Modernising' Data Protection Convention 108: A Safe Basis for a Global Privacy Treaty?," Computer Law \& Security Review 29, no. 4 (2013): 430-36, https://doi. org/10.1016/j.clsr.2013.05.015; Sophie Kwasny, “Convention 108, a Trans-Atlantic DNA?” in Trans-Atlantic Data Privacy Relations as a Challenge for Democracy, ed. Dan Jerker B Svantesson and Dariusz Kloza (Cambridge: Intersentia, 2017), 533-41.

35. Articles 54-55, Zakon o o zaštiti podataka o ličnosti, Sl. glasnik RS, br. 87/2018, 13.11.2018.

36. Article 22, Loi fédérale sur la protection des données (LPD), 25 septembre 2020, FF 20207397.

37. Article 17, ICRC Rules on Personal Data Protection, 12 June 2020, https://www.icrc.org/en/ publication/4261-icrc-rules-on-personal-data-protection.

38. Ann Cavoukian, Privacy by Design in Law, Policy and Practice. A White Paper for Regulators, Decision-Makers and Policy-Makers (Toronto: Information and Privacy Commissioner, Ontario, 2011).

39. Raphaël Gellert and Dariusz Kloza, "Can Privacy Impact Assessment Mitigate Civil Liability? A Precautionary Approach," in Transformation Juristischer Sprachen, from Tagungsband Des 15. Internationalen Rechtsinformatik Symposions IRIS 2012, ed. Erich Schweighofer, Franz Kummer, and Walter Hötzendorfer (Wien: Osterreichische Computer Gesellschaft, 2012), 497-505.

40. Dariusz Kloza, "Privacy Impact Assessments as a Means to Achieve the Objectives of Procedural Justice," in Transparenz. Tagungsband Des 17. Internationeln Rechtsinformatik Symposions IRIS 2014, ed. Erich Schweighofer, Franz Kummer, and Walter Hötzendorfer (Vienna: Osterreichische Computer Gesellschaft, 2014), 449-58.

41. David Parker, “(Regulatory) Impact Assessment and Better Regulation," in Privacy Impact Assessment, ed. David Wright and Paul De Hert (Dordrecht: Springer, 2012), 77-96, https:// doi.org/10.1007/978-94-007-2543-0_3.

42. Kloza et al., "Data Protection Impact Assessments in the European Union: Complementing the New Legal Framework towards a More Robust Protection of Individuals."

43. Frank Vanclay, "The Triple Bottom Line and Impact Assessment. How Do TBL, EIA, SIA, SEA and EMS Relate to Each Other?", Journal of Environmental Assessment Policy and Management 6, no. 3 (2004): 265-88, https://doi.org/10.1142/S1464333204001729.

44. Ryo Tajima and Thomas B. Fischer, "Should Different Impact Assessment Instruments Be Integrated? Evidence from English Spatial Planning," Environmental Impact Assessment Review 41 (2013): 29-37, https://doi.org/10.1016/j.eiar.2013.02.001.

45. Tajima and Fischer.

46. Based on, in particular: Roger Clarke, "An Evaluation of Privacy Impact Assessment Guidance Documents," International Data Privacy Law 1, no. 2 (2011): 111-20, https://doi. org/10.1093/idpl/ipr002; David Wright and Paul De Hert, "Findings and Recommendations," in Privacy Impact Assessment, ed. David Wright and Paul De Hert (Dordrecht: Springer, 2012), 445-81, https://doi.org/10.1007/978-94-007-2543-0_22; Dariusz Kloza, Niels van Dijk, and Paul De Hert, "Assessing the European Approach to Privacy and Data Protection in Smart Grids. Lessons for Emerging Technologies," in Smart Grid Security, ed. Florian Skopik and Paul Smith (Waltham, MA: Elsevier, 2015), 11-47, https://doi.org/10.1016/B978-0-12802122-4.00002-X; De Hert, Kloza, and Wright, "Recommendations for a Privacy Impact Assessment Framework for the European Union."

47. Cambridge Dictionary of English.

48. Based on, in particular: Kloza et al., "Towards a Method for Data Protection Impact Assessment: Making Sense of GDPR Requirements"; Kloza et al., "Data Protection Impact Assessment in the European Union: Developing a Template for a Report from the Assessment Process."

49. Sherry R. Arnstein, "A Ladder Of Citizen Participation," Journal of the American Institute of Planners 35, no. 4 (1969): 216-24, https://doi.org/10.1080/01944366908977225. 
50. See Annex 2 in this volume.

51. Astroturfing is a 'deceptive practice of presenting an orchestrated marketing or public relations campaign in the guise of unsolicited comments from members of the public' (Oxford Dictionary of English). The term 'astroturfing' - from an 'artificial grass surface used for sports fields' - was coined in order to directly juxtapose 'grass-roots', i.e. 'ordinary people regarded as the main body of an organization's membership' (Oxford Dictionary of English). 